\title{
Variaçōes sobre o tema: Um estudo comparativo de hemoglobinas de peixes (")
}

\author{
Jeffries Wyman (')
}

\section{Resumo}

E destacada a importância de estudar o comportamento das hemoglobinas em peixes, ressaltando a excepcional oportunidade oferecida pela disponibilidade do navio Alpha Helix. Quanto à união dos ligantes sob condições de equilíbrio, são dados vários exemplos das possibilidades de variação, disscutindo-se também outros aspectos das pesquisas tais como associação e dissociação na união do ligante, o fenômeno das fases regulamentadas, as flutuações de conformação das proteínas, a divisão da molécula entre dois ou mais ligantes e o efeito de fosfatos orgânicos e outras substâncias. Também são discutidos os ligantes sob estado de repouso e condições de transição, assim como a possibilidade de utilizar reações antigênicas cruzadas em pesquisas filogenéticas.

\section{INTRODUÇÃo}

Se a esta expedição fosse dado um nome, poderia bem ser denominada "Um Estudo das Variações sobre um Tema". O tema é hemoglobina, as variações, as diferenças nas propriedades e no comportamento, que tem sido desenvolvido no curso da evolução para satisfazer às necessidades particulares das diferentes formas animais. Filosoficamente, a iniciativa é de algum interesse: primeiro, como uma aventura na bioquímica comparada; segundo, como um intento de ganhar em profundidade dentro dos princípios operacionais no funcionamento geral das macromoléculas biológicas, tomando a hemoglobina como um caso típico; terceiro, o porquê das diferenças e semelhanças entre as hemoglobinas de diversas espécies, que podem ser, como as de outras proteínas, diagnóstico de afinidades filogenéticas.

Uma grande parte dos trabalhos prévios de hemoglobina tem sido dedicada à hemoglobina humana $(\mathrm{HbA})$ e seus derivados anormais, cujo número agora atinge a centenas. Muito também têm sido estudadas as modificaçöes químicas dos diferentes modos de uniỏes cruzadas. Evidentemente, um amplo campo estará aberto quando se estenda o estudo de hemoglobinas a outras espécies, confiando que a natureza produz $\alpha$ trabalho das modlficaçōes químicas. A escolha de hemoglobina de peixes para o presente trabalho foi sugerida pelo fato de que, em muitas, já se conhece que exibem um número excepcional e esclarecedor de propriedades. A escolha da Amazônia, como o lugar para este estudo, foi determinado pela grande riqueza da fauna daquele importante rio e pela acessibilidade para a excepcional disponibilidade do navio "Alpha Helix".

\section{UNIÃO DOS LIGANTES SOB CONDIÇŐES DE EQUILÍBRIO}

A hemoglobina, desempenhando um papel de transportador de oxigênio, funciona essencialmente em equilíbrio e muitos estudos realizados nos trabalhos seguintes foram feitos em sistemas de equilíbrio. Tais estudos têm a vantagem de que são levados sob as condições onde se verificam princípios de termodinâmica e a afinidade do ligante derivada dele são aplicáveis. A atenção pode ser dirigida também para o fenômeno de cooperatividade, envolvendo as interações homotrópicas entre os sítios, os quais unem o mesmo ligante ou também o fenômeno regulatório envolvendo interações heterotrópicas entre sítios, os quais unem diferentes ligantes. Na maioria das proteínas, as interações observadas, homotrópicas, têm sua origem nas mudanças conformacionais, na união de ligantes. Tais alteraçőes podem envolver uma simples mudança na disposição e contato numa região da macromolé-

( $)$ - Versão original inglesa publicada em Comp. Biochem. Physio. vol. 62A(1). 1979.

(1) - C.N.R. Centro de Biologia Molecular, Instituto de Química Biológica, Cidade Universitária 00185, Roma, Itália. O autor reconhecidamente agradece o patrocínio em forma de uma subverição da Fundação Nacional de Ciênclas dos Estados Unidos. 
cula ou, num caso extremo, a atual associação ou dissociação. No primeiro caso, referimonos ao efeito alostérico do ligante, no último, ao poliestérico. A causa da distinção é o tratamento analítico diferente aplicável aos dois tipos de ligantes.

Todas as relações termodinâmicas de ligantes aplicáveis ao sistema de equilíbrio podem originar-se de um grupo potencialmente derivável de energia pelo correspondente grupo de transformaçăo de Legendre (Wyman, 1975a). Um membro principal deste grupo é o que tem sido chamado potencial de união. No caso do sistema alostérico, pode ser este expresso como um logarítmo de um polinominal na atividade de vários ligantes; no caso do sistema poliestérico, nenhuma de tais formulações simples, é possível. Apesar disso, ambos os tipos de sistemas respondem a seus ligantes quase da mesma forma. Em ambas as mudanças conformacionais, sempre permite-se alcançar a cooperatividade (a qual pode naturalmente ser disfarçada pelo sítio heterogêneo) e, para ambos os ploteados de Hill, são muito semelhantes e são caracterizados por uma assimptota com uma unidade de inclinação a cada lado (Colosimo, et al., 1976).

A hemoglobina de vertebrados constituída por quatro cadeias ( 2 alfas e 2 betas), cada uma com um sítio simples de união de oxigênio, parece obedecer, pelo menos, a uma aproximação aos dois modelos alostéricos clássicos e seu comportamento pode ser interpretado adequadamente. Apesar disto, no entanto, há uma notável diferença em relaçäo aos efeitos homotrópicos e heterotrópicos. Sejanos permitido considerar um exemplo. No caso de hemoglobina humana, a curva de uniăo de oxigênio apresenta uma forte cooperatividade com um valor de coeficiente de Hill $n \simeq 3$, é uma das características exibidas por esta hemoglobina; é a invariabilidade da forma da curva de união (e ploteado de Hill) com a tempcratura e o pH. Baseado na teoria de ligantes, a invariabilidade de temperatura implica que o calor de oxigenação é independente do grau de saturação e este está de acordo com as recentes medidas calorimétricas de Atha e Ackers (1974) e de Gaud et al. (1974). Mais especificamente, em termos simples, há dois estados do modelo alostérico, isto significa que o calor de oxigenação de um sítio é o mesmo na forma $R$ como na forma $T$ da molécula. Similarmente, a invariabilidade de $\mathrm{pH}$ implica que o número de prótons Bohr liberados ou ocupados por " $\mathrm{mol}$ " de oxigênio unido é independente do grau de saturação, isto é, o número de prótons liberados é proporcional à saturação. Isto, igualmente, tem sido confirmado, pelo menos, como urna boa aproximaçăo em experimentos diretos. Em termos de modelo alostérico, implicase que o efeito Bohr principalmente, pelo menos, o local da cadeia é o mesmo para cada cadeia. Isto é compatível com deduções feitas de estudos de raios- $X$.

$\mathrm{Na}$ truta, a situação é radicalmente diferente (Brunori, 1975) . O sangue de truta, em vez de conter uma simples hemoglobina como o sangue humano, contém quatro, duas das quais, como unidades principais, săo designadas cơmo I e IV em relação a sua mobilidade eletroforética. Truta I năo apresenta efeito Bohr e, em qualquer caso, o valor de p1/2 é independente do $\mathrm{pH}$ e o calor de oxigenação é independente do calor de ionização do tampão usado no controle do $\mathrm{pH}$, como se na oxigenação não houvesse liberação de prótons. Nesta hemoglobina, o p1/2 é também, embora só dificilmente, independente da temperatura, como se o calor de oxigenação fosse zero. Este último, no entanto, é eluído, resultando, de qualquer forma, um inesperado e interessante fenômeno de compensação. Medidas calorimétricas precisas do valor principal de calor de oxigenação como uma função de saturação, mostra que estas mudanças quantitativas assinaladas durante 0 processo de união passando de um valor endotérmico a uma baixa saturação a uma unidade exotérmica e alta saturação $\left({ }^{2}\right.$ ) (Wyman et al., 1977). A dedução é que a curva de união, a diferentes temperaturas, deve cruzar-se em algum ponto, e isto é na verdade justificado com o que eles encontraram; sua forma varia grandemente

(2) - Atualmente, por motivos práticos, tanto estes es tudos calorimétricos, quanto os relacionados aos ligantes, foram feitos por substituição de $\mathrm{CO}$ pelo oxigê nio. No entanto, vendo a entalpia de uniăo de hemoglobina, há uma considerável similaridade entre estes dois ligantes, como têm sído estudados em tais casos. 
com a temperatura. De fato, pode-se predizer que, à temperatura suficientemente alta, toda a cooperatividade de união deve desaparecer. Em concordância com o modelo alostérico, o calor endotérmico está sendo associado com a forma $T$ e o calor exotérmico com a forma $\mathrm{R}$ da molécula de hemoglobina e é interessante te observar que o calor exotérmico associado com a forma $\mathrm{R}$ é ligeiramente similar ao calor de oxigenação de $\mathrm{HbA}$.

A hemoglobina Truta IV difere amplamente de ambas, $\mathrm{HbA}$ e Truta I. Ambas são muito sensiveis ao $\mathrm{pH}$ com respeito ao $\mathrm{p} 1 / 2$ e na forma da curva de união. Ao $\mathrm{pH}$ alto, onde o valor de $\mathrm{p} 1 / 2$ é similar ao de $\mathrm{HbA}$, a curva mostra alta cooperatividade $(\mathrm{n} \simeq 3)$; ao $\mathrm{pH}$ baixo. isto é grandemente aplanado e torna-se aproximadamente bifásica, no ponto meio, afasta-se para a direita de modo que começa a ser impossível a saturação da molécula mesmo com oxigênio puro, à pressão atmósférica. Esta forma de comportamento é conhecida como efeito Root e presume-se que prove a um mecanismo a $\mathrm{Hb}$ IV da truta que atua como uma bomba molecular para injetar oxigênio na bexiga natatória. Vale salientar que, diante desta ocorrência, a hemoglobina dá um belơ exemplo de uma macromolécula atuando como um "transducer" usando a energia livre derivada do fluxo de um ligante (proton) em uma direção para compensar o fluxo de um segundo ligante diferente (oxigênio). Formalmente, a situação é a mesma para o trabalho polifuncional da enzima sob condições de repouso como se descreveu alhures (Wyman 1975b). $\mathrm{Em}$ tais casos, a ação de bomba (usando o termo em sentido geral) é possível só pela eficiência de acoplamento envolvendo dois ligantes, provavelmente de origem alostérica ou polistérica, o qual é propiciado pela macromo. lécula.

Tenho exposto estes três casos como um exemplo de classe de variação que podem ser vistos, em tais estudos, comparativos como uma atualidade, porém há naturalmente muitos outros aspectos significativos do comportamento molecular, os quais podem igualmente ser investigados sob condições de equilibrio. Entre eles, posso mencionar os seguintes: (1) associação e dissociação na união de ligante. Na forma oxigenada, $\mathrm{HbA}$ dissociada, a uma diluição suficientemente alta, em dímeros $\propto \beta$, enquanto sob as mesmas condições, as moléculas desoxigenadas permanecem, na maioria, completamente tetramérica. Em comparação com $\mathrm{HbA}$ as hemoglobinas da truta, quer ligadas ou desligadas, são quase não dissociáveis. O fenômeno de dissociação na união do ligante, o qual é uma expressão de forças operantes nas superfícies de contactos das subunidades, isto é, estritamente relacionado à questão de energia livre de interação nos sítios de união de oxigênio na molécula não dissociável (2) fenômeno de fases regulamentadas. É sabido que as formas oxigenadas de hemoglobinas tetraméricas, a diferença das mioglobinas, monoméricas, em diversas formas cristalinas, caracterizadas por diferentes solubilidades. Em alguns casos, isto é oxi e em outros deoxi, a qual é a mais solúvel, seguindo as considerações da fase regulamentada, estas podem ter um valor de pressão parcial do oxigênio na qual as três fases solução, oxiemoglobima cristalina e deoxiemoglobina cristalina - podem coexistir. Poderia ser interessante investigar como estas características tríplices assinaladas variam a estrutura da molécula de hemoglobina. Estritamente relacionado com isto, é o assunto do calor de solução das duas classes de cristais. Baseado no modelo alostérico, um dele poderia corresponder à forma $T$ e outro à forma $R$, e o estudo poderia prever informação como, por exemplo, a energia latente das duas formas. (3) Flutuações. Tem sido agora provado que muitas proteínas (provavelmente todas) revelam flutuações de conformação sob condições constantes. Isto tem sido verificado por ambos os estudos, intercâmbio de isótopos e unidades óticas, destas particularmente envolvendo fluorescências. Tais flutuações ocorrem sempre envolvendo mudanças de energia livre isto é suficientemente pequena em relação $\mathrm{KT}$, como deve certamente ser para a transição da forma $T$ para $R$ no caso clássico de dois estados de sistema alostérico, onde naturalmente a transição de energia livre está controlada pela presença ou ausência de ligante. Isto é significativo: as flutuações observadas apontam um espectro de tempos de relaxação no limite do nono seguncio, a hora ou ainda a 
dias. (4) A divisão da molécula entre dois ou mais ligantes, como o exemplificado pela hemoglobina na presença de oxigênio e monóxido de carbono, dois ligantes que competem no mesmo sítio. (5) 0 efeito de fosfatos orgânicos e outras substâncias, notavelmente variados ions inorgânicos, na afinidade de oxigênio e dissociabilidade de hemoglobina. (Isto é um fenômeno que recebe uma considerável atenção em alguns dos trabalhos a segurr).

\section{LIGANTES SOB ESTADO DE REPOUSO}

E CONDIÇÕES DE TRANSIÇÃo

Até aqui, eu mesmo tenho limitado o fenômeno realizado sob condições de equilíbrio. Muitas macromoléculas biológicas, notavelmente enzimas, não operam em equilíbrio porém sob condiçōes de estado de repouso. Se a hemoglobina é usada como um protótipo de tais macromoléculas, claramente deve ser estudada em estado de repouso, mais apropriado que as condições em equilíbrio. Quando passamos do equilíbrio ao estado de repouso naturalmente, não por muito tempo, fazemos uso do princípio termodinâmico clássico; em seu lugar, devemos ter o auxílio da equação cinética, a qual descreve o sistema (Wyman et al., 1975b). No caso de macromoléculas, que existem em conformações variadas na presença de seus ligantes, teriam uma equação para cada forma da molécula, tomando em conta as várias conformações como também os diferentes estados de ligação. Cada equação dará o tempo derivado da quantidade da forma correspondente em termos da quantidade diferenciada da forma total, a constante cinética e atividade de ligantes. Se as atividades dos li. gantes são consideradas constantes e se a macromolécula não está dissociada, esta será linear acopladas às equações de primeira ordem. Neste caso, contanto que a quantidade de macromolécula permaneça constante, podese deduzir que haverá sempre um único estado de repouso (ponto crítico) definido pela solução de equações com cada derivada de tempo igual a zero, e este sistema será assimptoticamente estável ao redor deste ponto; que não é o caso da condição inicial; a aproximação deste ponto de relaxação $n-1$, onde " $n$ " é o número de formas diferentes da macromolécula. Estes tempos de relaxação são dados pela equação secular de grau " $n$ " da solução, na qual a unidade de origem é zero, derivada da equação cinética dirigente. $O$ equilíbrio é simplesmente um caso especial onde a constante cinética satisfaça às condições de balanço microscópico.

Quando a macromolécula dissociada, ou quando a quantidade de ligantes é mantida constante, de preferência a uma atividade constante, a equação governante poderá năo ser linear por muito tempo e, em geral, năo haverá solução analítica, ou as condiçōes de balanço microscópico não serão satisfeitas, no entanto, observando as coisas qualitativamente da maneira introduzida por Poincaré e Liapounov para tais casos, inferimos, embora sem prova, que proporciona a quantidade total da macromolécula que persistem constantes nesse ponto haverá ainda um ponto crítico (Estado de repouso), ao redor do qual o sistema é assimptoticamente estável. Neste caso, entretanto, não haverá uma equação secular e conseqüentemente não poderíamos expressar o processo de relaxação em termos de uma fração finita, os tempos de relaxação embora as equações sejam lineares (Esta conclusão é naturalmente óbvia quando o estado de repouso é um equilíbrio verdadeiro) .

É importante observar que, sob ambos os estados de repouso e condiçōes transitórias as equações cinética são uma fonte de relação de acoplamento não menos precisa, embora de formulação menos simples, que as derivadas do princípio termodinâmico para um sistema em equilíbrio. Num caso simples, onde a equação do estado de repouso é linear, a quantidade relativa das várias formas da macromolécula é dada por cofatores apropriados escoIhidos, determinando a invenção do coeficiente das variadas formas na equação (Wyman, 1975b) $\left({ }^{3}\right)$. É interessante observar que continuando com isto sob as condições apropriadas, um estado de repouso pode ser alcançado para

(3) - A quantidade relativa de várias formas poderiam $\mathrm{n}$ aturalmente variar conforme as condições. Isto, por exemplo, as formas que são desprezíveis ao equilibrio, podem tornar-se visíveis ou equilibradamente predominantes sob condiçōes de repouso. 
uma cooperatividade de uniäo que poderá ser totalmente impossivel sob condiçôes de equilíbrio, assim o valor do coeficiente de Hill " $n$ " pode exceder ao número de sítios na macromolécula. Por esta razão, baseado só nos dados de união pode ser impossível distinguir entre o verdadeiro equilíbrio e um estado de repouso, embora que uma determinação exata da assimptota superior de um plóteo de Hill, se praticável, pode ser decisivo: um valor maior que 1 é indicativo de um estado de repouso.

Objetivando empregar a hemoglobina como um protótipo de enzima trabalhando sob condições de repouso, poderíamos ter a vantagem da extrema fotossensibilidade deste composto com monóxido de carbono. Estudando $\mathrm{Hb} \mathrm{CO}$ na presença de variadas quantidades de luz, estaremos de fato, estudando uma macromolécula em um estado de repouso. A relaxação que é revelada quando a luz é afastada ou esta intensidade alterada será mais representativa do que poderia ser esperado de uma enzima quando as condições de trabalho são subitamente mudadas. Um fenômeno transitório deste tipo que ocorre sob tais condições são amplamente significativos em conexão com a visão e outros fenômenos sensoriais, na verdade, geralmente na biologia. Que, depois de tudo, ê a vida, senão uma seqüência transitória incompleta?

\section{REAÇÕES CRUZADAS DE ANTÍGENO E ANTICORPO}

Como um assunto fora do parágrafo aberto, uma comparação das propriedades de hemoglobinas de diferentes espécies pode dar uma informação útil orientando as relaçōes filogenética. Uma ilustração disto é provida pelos experimentos inmunológicos descritos em um dos trabalhos a seguir. Nos experimentos, ai descritos, anticorpos foram preparados contra três hemoglobinas de peixes, isto é, a carpa, truta I e truta IV e a reação cruzada destes anticorpos foram estudado com as hemoglobinas de outras espécies de peixes. Resumindo os resultados sem detalhes, podemos dizer que cada um dos três anticorpos (e deste modo com cada um dos peixes correspondentes) pode ser identificado como uma reação cruzada caracterizando as hemoglobinas. Além dis- so, foi possível fracionar anticorpos por procedimentos inmunológicos apropriados e, quando isto foi feito, notou-se que cada fração poderia ser identificada com um subgrupo de hemogla binas, que reagem com o anticorpo original não fracionado. Pareceria que uma maneira proveitosa do procedimento com experimentos desta classe dirigidos até as relações filogenéticas, poderia ser em termos de um grupo teórico, desse modo fazendo o possível para aplicar simples métodos para grupos, tais como os relatando uma adição, subtração e intersecção expondo e analisando os resultados.

\section{UMA LINGUAGEM BIOLÓGICA}

Torna-se, não obstante, em pequena consideração para convencer-nos a nós mesmos da fundamental importância para a biologia, fenômeno de união a qualquer nível, tomando-o num sentido mais geral, i.e. o reconhecimento e união de substâncias específicas por sítios específicos e interatuando na união. Isto é o que faz possível o controle de reações de macromoléculas, que dirigem sua união como também as de maioria das estruturas, que encontram expressöes no fenômeno inmunológico, que existe baseado na quimostácia mostrada por células e organismos, e, a nível superior, tais casos de comportamento estão representados como resposta de um inseto a um fenômeno. Examinando os fatos amplamente, todas estas coisas podem ser imaginadas como um momento de percepção e neste sentido de percepção pode ser explicado como uma linguagem biológica.

$\mathrm{Na}$ grande maioria dos casos, a forma de comunicação íntima desta linguagem, i.e. o modo pelo qual a mensagem é entregue desde um sítio de interação a outro, encontrou-se na mudança conformacional induzida pelos ligantes; estas mudanças conformacionais unidas aos ligantes; efetores alostéricos possivelmente podem ser um mecanismo de fala. E equivalente à gramática? Muitas linguagens têm as regras da gramática. É natural pergun. tar-se, portanto, onde residem essas linguagens de percepção. As respostas estão claras: elas residem minuciosamente naquelas relaçōes de uniões básicas, para os sistemas em equilíbrio, são dadas por um apropriado grupo 
de potencial termodinâmico, e para os sistemas em um estado de repouso, estão implícitas nas equações cinéticas, lineares ou não lineares. As hemoglobinas fornecem uma excepcional oportunidade para estudar esta linguagem biológica fundamental.

\section{SUMMARY}

The importance of studying hemoglobin behaviour in fish is discussed, noting the exceptional oportunity for this aboard RV Alpha Helix. Several examples are given of ligand binding under equilibria. Several possibilities for further research are also discussed, such as association and dissociation in ligand binding, the phenomenon of regularized phases, fluctuations of protein conformation, division of the molecule between two or more ligands and the effect of organic phosphates and other substances. Also discussed are ligands in resting state and under transition, as well as the possibility of using antigenic reactions in phylogenetic research.

\section{BIBLIOGRAFIA}

ATHA, D.H. \& ACKERS, G.K.

1974 - A Calorimetric Determination of the Heat of Oxygenation of Human Hemo- globin as a Function of $\mathrm{pH}$ and the Extent of Reaction. Biochemistry, $13: 2376-2382$

BRUNORI, M.

1975 - Molecular Adaptation to Physiological Requirements: The Hemoglobin System of Trout. Curr. Top. Cell. Reg. 9:1-39.

Colosimo, A.; Brunori, M. \& Wyman, J.

1976 - Polysteric Linkage. J. Mol. Biol., 100 : 47-57.

Gaud, H.T.; Barisas, P.G. \& Gill, S.J.

1974 - Enthalpy Changes for Hemoglobin lingand Interactions: Resvised calorimetric data. Biochem. Biophys. Res. Comm., 5 : 1380-1394.

WYMAN, J.

1975a - A Group of Thermodynamic Potentials Applicable to Ligand Binding by a Polyfunctional Macromolecule. Proc. Nat. Acad. Sci. U.S.A., $72: 1464-1468$.

$1975 \mathrm{~b}$ - The Turning Wheel: A Study in Steady States. Proc. Nat. Acad. Sci. U. S. A., $72: 3983-3987$.

WYMAN, J.; GILL, S.J.; MOLL, L.; GIARDINA, B.; COLOSIMO, A. \& BRUNORI, M.

1977 - The Balance Sheet of a Hemoglobin: The Thermodynamics of $\mathrm{CO}$ Binding by Hemoglobin Trout 1. J. Mol. Biol., 109: 195-205 